\title{
Organ donation after medical assistance in dying at home
}

\author{
Johannes Mulder MD PhD, Johan P.C. Sonneveld MD PhD
}

Cite as: CMAJ 2018 November 5;190:E1305-6. doi: 10.1503/cmaj.170517

M

edical assistance in dying (MAiD) is regarded as compassionate care in countries where it is permitted. ${ }^{1}$ Increasingly, patients considering MAiD have requested that the procedure be followed by organ donation..$^{2,3}$ Although the criteria for MAiD differ by country, the combination procedure is of interest to any country that has legalized MAiD. ${ }^{4}$

In the Netherlands, the combination of MAiD followed by organ donation is legal and endorsed by Eurotransplant., 5 Medical assistance in dying is generally performed in the comfort of the patient's home by their family physician. ${ }^{7}$ However, adding organ donation has resulted in MAiD being performed in hospital because of the limited time permitted between circulatory arrest and organ procurement. ${ }^{8}$ Ultimately, some patients chose not to proceed with organ donation primarily because of the requirement to die in the hospital. ${ }^{9}$

To facilitate organ donation after MAiD in the Netherlands, a clinical practice guideline was developed and presented to the Minister of Health in March 2017.9,10 The aim of the guideline was to fulfill a patient's final wish of donating organs after MAiD, while protecting autonomous choice and minimizing the disruptive effect. The focus is on the patient's wish to do good rather than on expanding the organ donation pool.

We describe the procedures developed in the Netherlands to provide MAiD at home followed by organ donation.

\section{What is organ donation after medical assistance in dying at home?}

We developed a procedure as one possibility to allow people who are ill and who would like to receive MAiD to fulfill their desire to donate their organs, with minimal disruption to the dignity of dying in their own home. ${ }^{11,12}$ The key is temporizing MAiD by using an anesthesia bridge to separate the experience of dying at home from subsequent biological death and organ donation in hospital. The procedure was designed in co-operation with relevant stakeholders, including the public prosecutor, and the ethics board and executive board of the participating hospital. The public prosecutor deemed the procedure legally equivalent to MAiD and organ donation procedures performed separately, and acceptable when "due care" criteria ${ }^{1}$ are met. The ethics board welcomed the procedure because it is primarily designed to fulfil a dying patient's final wish to benefit others while retaining optimal end-of-life care.

\section{KEY POINTS}

- A person contemplating organ donation after medical assistance in dying (MAiD) must not be regarded as an organ donor but as a person wishing to do a good deed at the end of life.

- Safeguards must be in place to ensure the patient's autonomy and nonmaleficence while preserving quality of the organ donation.

- Use of an anesthesia bridge for travel between the patient's home and the hospital allows for organ donation after MAiD at home.

- This procedure makes it possible to fulfill the final wishes of patients requesting MAiD to donate their organs while dying at home.

The board stressed the importance of strict patient autonomy and clear separation of the decision for MAiD and organ donation. The hospital executive board endorsed the process as a new societal development of patient rights and emphasized the need to develop a supported protocol.

\section{How is medical assistance in dying delivered?}

When the family physician is discussing end-of-life options with the patient, organ donation after MAiD at home can be considered at the patient's explicit wish. ${ }^{6,11,12}$ Organ donation should not be raised or discussed until the patient has determined that he or she wishes to receive MAiD, because these decisions must not influence each other. Furthermore, the patient must be fully informed of the practical consequences of adding organ donation. If the patient wishes to start the procedure and due care requirements ${ }^{1}$ are met, the family physician contacts the hospital donation coordinator to confirm donation eligibility and makes arrangements with the anesthesiologist-intensivist. Logistics must be determined in consultation with the patient so that the anesthesiologist-intensivist and ambulance personnel can be present at the patient's home at the moment when MAiD is started.

On the appointed day, with the anesthesiologist-intensivist attending out of sight of the patient and after the patient's conscious last farewells, the family physician administers a sedative (midazolam). The patient gradually falls asleep; when the patient becomes nonresponsive, the family physician indicates to the waiting anesthesiologist-intensivist that it is time to perform induction of anesthesia with propofol and endotracheal intubation. The 
family can say their last farewells to the unconscious patient and, when they are ready, the ambulance transfer to hospital takes place. In the hospital, the family physician administers the drugs for the MAiD procedure and, after death, a regular organ procurement procedure follows. ${ }^{1,8}$ Within four hours, the patient's body can be returned home by the family's chosen funeral director. ${ }^{8}$

\section{Who is eligible?}

First, the due care requirements for MAiD must be met, which may differ by country. ${ }^{1}$ Second, the patient must be eligible for organ donation, requirements for which may also differ by country. About $80 \%$ of patients requesting MAiD in the Netherlands have cancer and are ineligible for organ donation; other exclusion criteria include serious infections and specific organ exclusions with kidney disease, pulmonary disease, liver cirrhosis and type 1 diabetes. ${ }^{11,12}$ Patients with neurodegenerative diseases most commonly request the combination procedure in the Netherlands. ${ }^{11}$

\section{What are the possible harms?}

Safeguarding patient autonomy can be a challenge for the family physician performing MAiD, particularly in view of the competing interests of organ donation. Organ donation after MAiD must always be the patient's autonomous choice, and the organs procured must remain a secondary benefit and never the reason for the procedure. The patient must also not perceive any pressure in reaching a decision and must feel free to withdraw consent up to the last second of conscious life.

The logistics may also present a challenge. When deciding to start the procedure, the patient generally does not wish to wait long. The family physician has to work with the anesthesiologist-intensivist and donation coordinator to organize procedural aspects promptly. Ideally, protocols are in place and can be triggered.

A potential risk is physiologic destabilization during transport to the hospital of the patient who has been anesthetized. In the worst-case scenario, MAiD must be concluded in the ambulance. Although this outcome rules out donation, there are no further consequences because the patient's intention was to die.

A further possible challenge might be the ethical acceptability of organs procured by MAiD and given to recipients, although this appears to not be an issue in the Netherlands.

\section{What is the evidence so far?}

Organ donation after MAiD has taken place about 40 times in the Netherlands with good results. ${ }^{6}$ The organs procured were kidneys, livers and lungs. Organ donation after MAiD at home has been performed twice, resulting in the procurement of the same organs..$^{11,12}$ The procedure has been well received, in particular by the patient while conscious, the patient's family and the organizations involved. ${ }^{8,11}$ The first case was accompanied by a broadcast (available at www.npostart.nl/als-patient-donates-his-organs-after -euthanasia/11-05-2017/POMS_AT_8838678), in which the patient expressed positive views on the procedure. The family physician, hospital staff and ambulance personnel evaluated the procedure as effective and rewarding because they witnessed the satisfaction of the patient and family. The main issues were logistics and investment of time by the anesthesiologist, because an extra burden is imposed by the attendance requirement outside the hospital.

\section{What can be expected in the future?}

With the successful implementation of organ donation after MAiD at home, we anticipate that this procedure will become more common because of the advantages for the patient.

\section{References}

1. Guidelines for the practice of euthanasia and assisted suicide. The Netherlands: Royal Dutch Medical Association (KNMG)/Royal Dutch Pharmacists Association (KNMP); 2012. Available: www.knmg.nl/advies-richtlijnen/dossiers/euthanasie/ viewpoints-and-guidelines-euthanasia.htm (accessed 2018 Feb. 16).

2. Blommers C. Dying yourself and saving five people's lives [article in Dutch]. Algemeen Dagblad 2014 Oct. 18. Available: www.ad.nl/gezond/zelf-sterven-en-vijf -mensen-het-leven-redden a21b1c53/ (accessed 2018 Feb. 16).

3. Pauls K. Organ donation changes dying for those getting medically assisted death. CBC News 2018 Jan. 4. Available: www.cbc.ca/news/canada/manitoba/ dying-organ-donation-benefits-1.4405020 (accessed 2018 Feb. 16).

4. Allard J, Fortin MC. Organ donation after medical assistance in dying or cessation of life-sustaining treatment requested by conscious patients: the Canadian context. J Med Ethics 2017;43:601-5.

5. Schippers El. Answers to questions by MP Tellegen regarding restriction on donation after euthanasia [article in Dutch]. Available: https://zoek.officiele bekendmakingen.nl/ah-tk-20142015-1474.html (accessed 2018 Feb. 16).

6. Oosterlee A, Rahmel A, editors. Eurotransplant International Foundation annual report 2008. Leiden (The Netherlands): Eurotransplant International Foundation; 2008. Available: www.eurotransplant.org/cms/index.php?page=annual_reports (accessed 2018 Feb. 16).

7. Regional Euthanasia Review Committees. Annual report 2016 [in Dutch]. Available: https://zoek.officielebekendmakingen.nl/blg-804950.pdf (accessed 2018 Feb. 16).

8. Model protocol for post-mortal organ and tissue donation [article in Dutch]. Leiden (The Netherlands): Dutch Transplant Foundation; 2018. Available: www.transplantatiestichting.nl/sites/default/files/modelprotocol_postmortale_ orgaan-_en_weefseldonatie.pdf (accessed 2018 Feb. 16).

9. Mulder H, Olthuis $\mathrm{G}$, Siebelink M, et al. Guideline on organ donation after euthanasia [abstract]. Dutch J Med 2017;161:D2135. Available: www.ntvg.nl/ artikelen/richtlijn-orgaandonatie-na-euthanasie/abstract (accessed 2018 Feb. 16).

10. Increased clarity on organ donation after euthanasia. Minister of Health Edith Schippers receives the new guideline on organ donation after euthanasia [article in Dutch]. Leiden (The Netherlands): Nederlandse Transplantatie Stichting; 2017 Mar. 8. Available: www.transplantatiestichting.nl/nieuws/meer-duidelijkheid -over-orgaandonatie-na-euthanasie (accessed 2018 Feb. 16).

11. Mulder J, Sonneveld JPC. Organ donation following euthanasia starting at home. Transpl Int 2017;30:1075-6.

12. Mulder J, Sonneveld J. Organ donation following physician-hastened death at home [article in Dutch]. Ned Tijdschr Geneeskd 2017;161:D1779.

\section{Competing interests: None declared.}

This article has been peer reviewed.

The authors have obtained patient consent.

Affiliations: Intensive care department, Isala Hospital (Mulder, Sonneveld), Zwolle, The Netherlands

Contributors: Both authors contributed to the conception and design of the work, and the acquisition, analysis, and interpretation of data. Both authors drafted the manuscript, revised it critically for important intellectual content, gave final approval of the version to be published and agreed to be accountable for all aspects of the work.

Correspondence to: Johannes Mulder, hjghm@xs4all.nl 